\title{
Rethinking Experiential and Hands-On Learning for Digital Spaces: A game-based case study in design education
}

\author{
Kristina Maria Madsen ${ }^{a^{*}}$, Thessa Jensen ${ }^{\mathrm{b}}$ \\ ${ }^{A}$ Aalborg University Business School \\ ${ }^{B}$ Aalborg University, Department of Communication \& Psychology \\ *Corresponding author e-mail: krma@business.aau.dk
}

\begin{abstract}
:
The experiential learning cycle by Kolb is used as a basic framework for connecting abstract concepts like creativity with the design thinking process in a digital online course environment. The students contemplated each step in the learning cycle at least twice in an onward learning spiral. We as teachers completed the cycle on a meta-level, beginning with the abstract conceptualization of the course materials, theories, and methods, and ending with writing this article. The design thinking process applies second-order learning, where the students utilize theories, methods, and actual experiences in the design of their prototype, the testing of which gives new actual experiences, which in turn are reflected upon and finally conceptualised in the concluding exam. Our findings show that despite the challenges of transferring a course from a physical setting to an online environment, teaching and learning, as well as group work are possible.
\end{abstract}

Keywords: experiential learning, design thinking, creativity, virtual learning spaces, digital tools

\section{Introduction}

With the national and international lockdowns during the coronavirus pandemic of 2020-2021, university employees and students in Denmark had to stay at home to self-isolate, while teaching and learning were transformed into a fully online setting. At Aalborg University, Denmark, we had to rethink our design and workshop-driven course in Creativity \& Competence for undergraduates at the Department for Communication and Psychology, Faculty of Humanities.

This meant that providing a hands-on workshop for experiment and exploration facilitated learning had to be conducted through digital space and thereby forcing us to rethink our teaching approach. Our goal changed from merely teaching creative theories and design methods to giving the students an understanding and working knowledge of their online environment as well. Kolb's experiential learning cycle (Kolb, 2015; figure 1) was issued as our basis for transforming this course into an online digital setting. This means that the students need to learn abstract concepts, like 
Csikszentmihalyi's system model of creativity, experience actual creative thinking and development through the experiments with the board games, realize how the different online platforms could be used to create their workshop, and, finally, create a working prototype and test it on their fellow students.

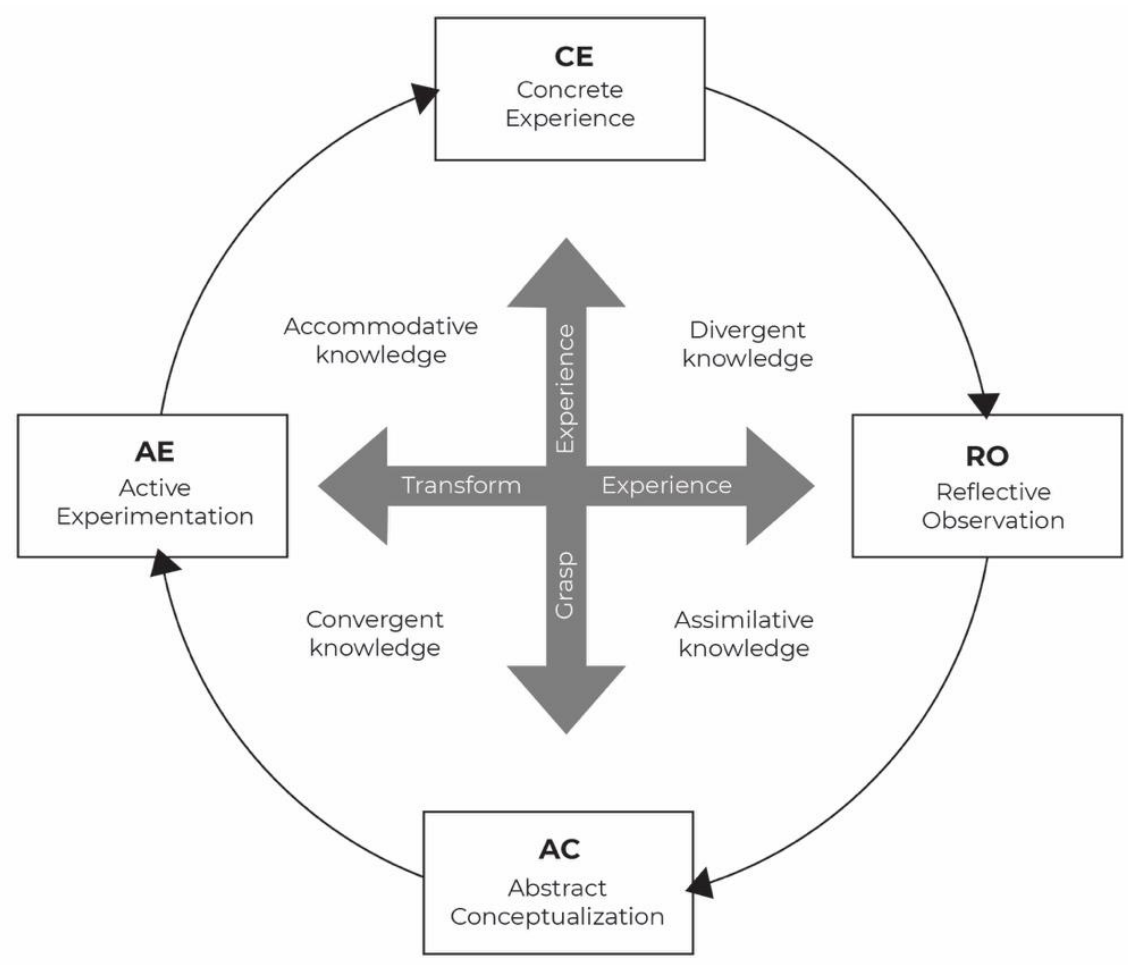

Figure 1: Kolb's experiential learning cycle. Drawn based on Kolb (2015)

Through this case study, we aim to discuss and explore how we can rethink hands-on learning in a digital space by applying an experiential learning approach combined with a design thinking process and game-based methods facilitating creativity.

\section{Hands-on learning in a digital space - the case}

The purpose of the Creativity \& Competence course is to introduce and practice competencies concerning creative, artistic processes and to use these in an individual and collaborative concept development of media products. The student should acquire knowledge of the management of artistic processes. The course is based on Csikszentmihalyi's (2014) system perspective which, during the course, is expanded with further approaches to the concept of creativity. Working with creative processes, the students should be able to relate to both the individual as well as the collaborative aspects of creativity. The course intends to provide the students with insight into, and understanding of, the built-in mechanisms of the processes, and into how methods can accommodate their resistance or pressure when applied to a design process. Following a theoretical perspective of creativity, the course introduces games as a method to facilitate creativity and how this type of creative method can be applied to the students' project work. The course ended with a 3-days individual assignment.

The course is divided into five modules (figure 2). Each module consists of four lessons, 45 minutes each. Except for the first module, both teachers were present during the whole course. Sixteen 
students participated in the course. We divided the students into four groups, four students in each one. For this particular course, we chose Zoom for theoretical lectures, Microsoft Teams for group work activities, and the brainstorm platform Padlet as our workshop environment. At the time of the course-February 2021-we had already been through several lockdowns, giving us ample experience with online teaching and supervision.

\begin{tabular}{|c|c|c|c|c|}
\hline $\begin{array}{l}\text { M1: Theory } \\
\text { Introduction to } \\
\text { foundational } \\
\text { creativity theory }\end{array}$ & $\begin{array}{l}\text { M2: Game-play } \\
\text { Introduction to } \\
\text { games as a } \\
\text { method + } \\
\text { hands-on } \\
\text { game-play } \\
\text { experience with } \\
\text { 'The OMGame' }\end{array}$ & $\begin{array}{l}\text { M3: Game-play } \\
\text { Introduction to } \\
\text { contexts for } \\
\text { creativity + } \\
\text { hands-on } \\
\text { game-play } \\
\text { experience with } \\
\text { 'Cards for loT' }\end{array}$ & $\begin{array}{l}\text { M4: Game } \\
\text { Creation } \\
\text { Students } \\
\text { gamifying } \\
\text { an interview } \\
\text { method }\end{array}$ & $\begin{array}{l}\text { M5: Test } \\
\text { Presentation } \\
\text { and testing } \\
\text { the gamified } \\
\text { method + } \\
\text { reflection on } \\
\text { creativity } \\
\text { theory }\end{array}$ \\
\hline
\end{tabular}

Figure 2: An overview of the courses 5 modules, which will be unfolded in the following sections 2.1-2.4.

\subsection{M1: Foundational Creativity Theory}

The theoretical curriculum for the course consists of the system model of creativity by Csikszentmihalyi (2014), Amabile's creativity theory (1998), and Rhodes four elements of creativity (1961). The first module of the course introduces these concepts of creativity both from a broad historical perspective and with certain theories of creativity. While this module was mostly a lecture presenting the different theories, smaller tasks were assigned to the students. Rhodes' (1961) four p's of creativity: person, process, press, and product, were turned into four presentations by the students. The student had to discuss the different theories of creativity with each other. This was done in breakout rooms. While the platform was new for the students, the type of lecture was familiar in its way of presenting abstract concepts. The students learned via assimilation of the theoretical concepts of already existing knowledge.

\subsection{M2+M3: Gameplay}

The methodological curriculum consists of the design thinking process of the Hasso Platner Institute of Design at Stanford University (Stanford d. school, 2019). To facilitate a hands-on understanding of methods and theory, two board games are used to show how an innovative and creative process can be facilitated in a museum and a business setting. In a third workshop, the students themselves develop a gamified method. Each workgroup is assigned a specific interview method and a basic user scenario. The students add self-selected game elements to the assigned method, thus gamifying the setup. Usually, this is done in a face-to-face setting, where the students are working together, using the board games and other materials to brainstorm and design their prototype.

Through the second and third modules, the students were introduced to gamification as a method concerning creativity in development processes. They were given a short introduction to the context and starting point for the games [M2: Exhibition design \& Museum roles - M3: Business Models \& IoT]. In addition, the students were introduced to the games and their structures, to make sure that they could start and facilitate the play-sessions, easily. After the introduction, the students worked in the group channels in Teams, playing the games on each of their Padlet game boards. Each group chose a gamemaster ensuring proper facilitation of the game. The students could contact us at any time during the modules if need be. The dialogue about the game took place in Teams while interacting on their group assigned Padlet game board. When the game session concluded, the 
groups were asked to reflect on their gaming and learning experience using a recap Padlet (figure 3 ). This was followed by group presentations and a general discussion.

Each gameplay was active experimentation, moving the theoretical understanding of creativity from assimilation to accommodation, grasping the experience of creative thinking, and transforming it into a deeper understanding of the processes involved. The recap Padlet forced the students to articulate their experiences and reflect on action (Schön 1987), both regarding concrete gaming and creative thinking experience, as well as connecting the theoretical concepts of creativity with the practical application of the same.

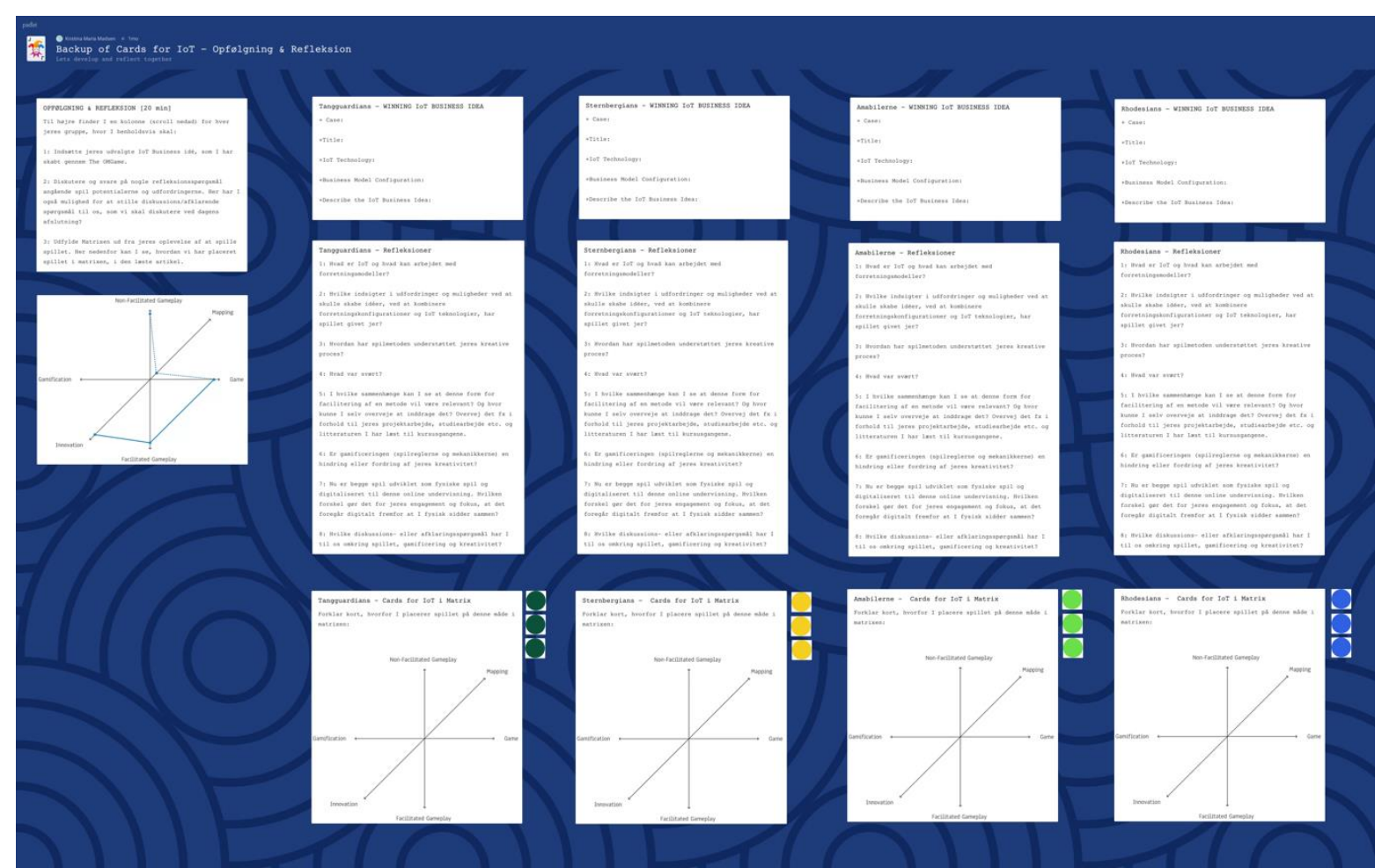

Figure 3: A visual of the recap and reflection Padlet board that the students had to fill out.

\section{Modifying physical game methods for digital hands-on workshops}

By using the Padlet platform for our digital versions of the board games, we maintain the interaction potential of the physical board games. All the physical components are embedded as pictures (cards, roles, user types, museum types \& tokens) or text boxes (questions, instructions, time, rules \& collection), so the students can move, write and add components while playing - as if they were sitting together around a table, playing the physical games. The games used in module $2+3$ were 'The Our Museum Game' (OMG) (Madsen \& Krishnasamy, 2020), figure 4 shows the physical game and figure 5 shows the digital Padlet version; and 'Cards for loT' (Madsen \& Rasmussen, 2021), figure 6 showing the physical game and figure 7 showing the digital Padlet version of the game. 


\section{THE OUR MUSEUM GAME}

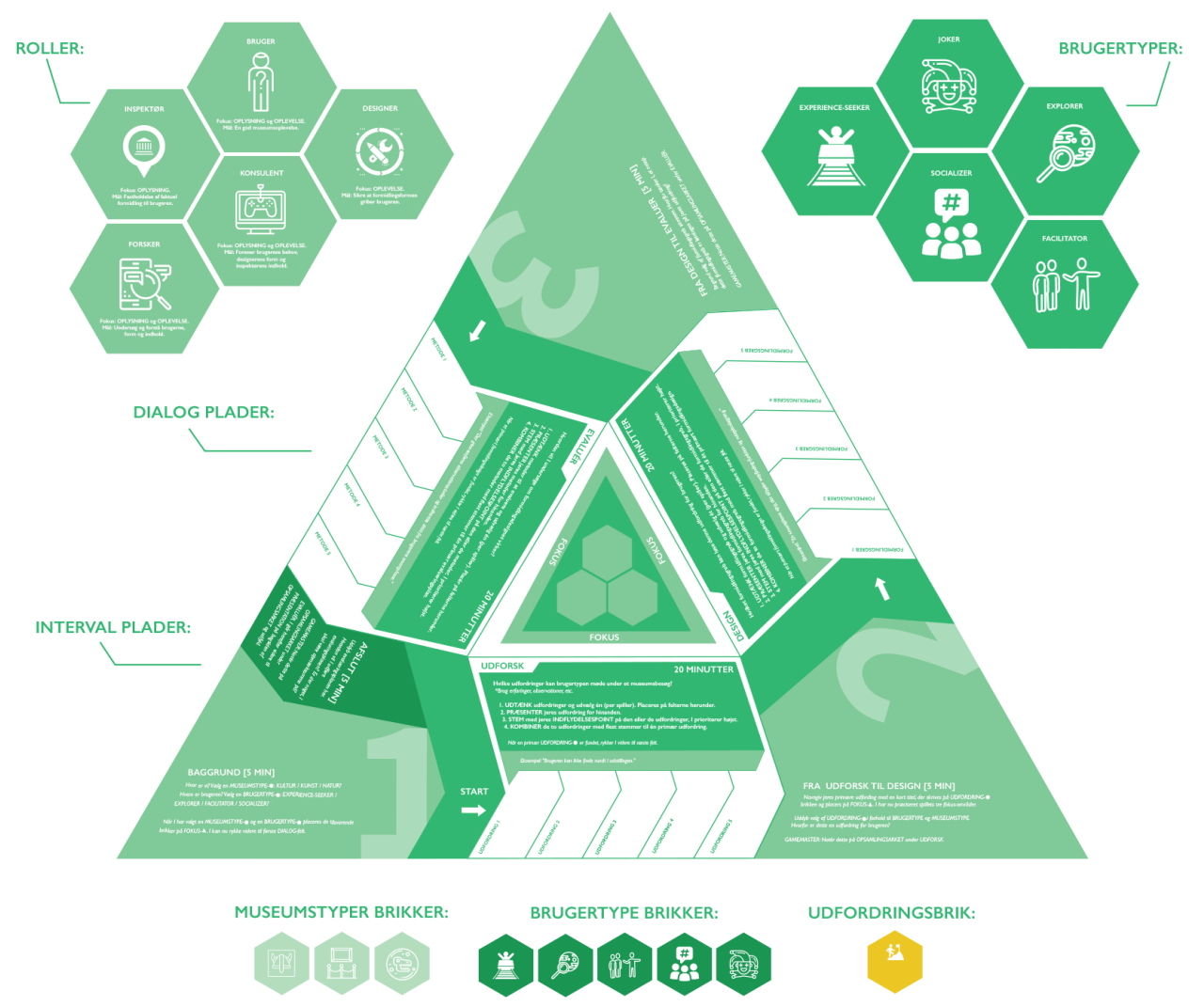

Figure 4: The visual setup of the physical OMGame.

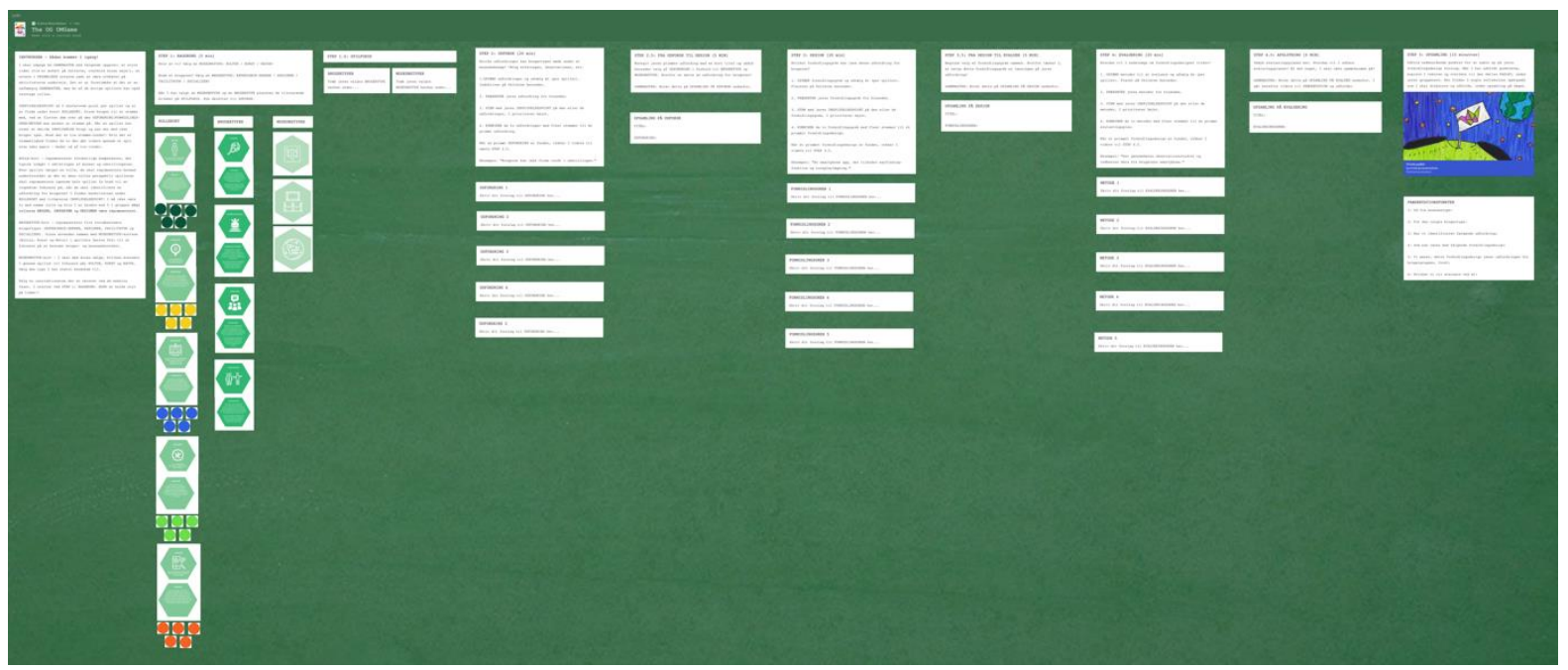

Figure 5: A visual of the digital Padlet version of the OMGame, which each group were assigned to play through. 

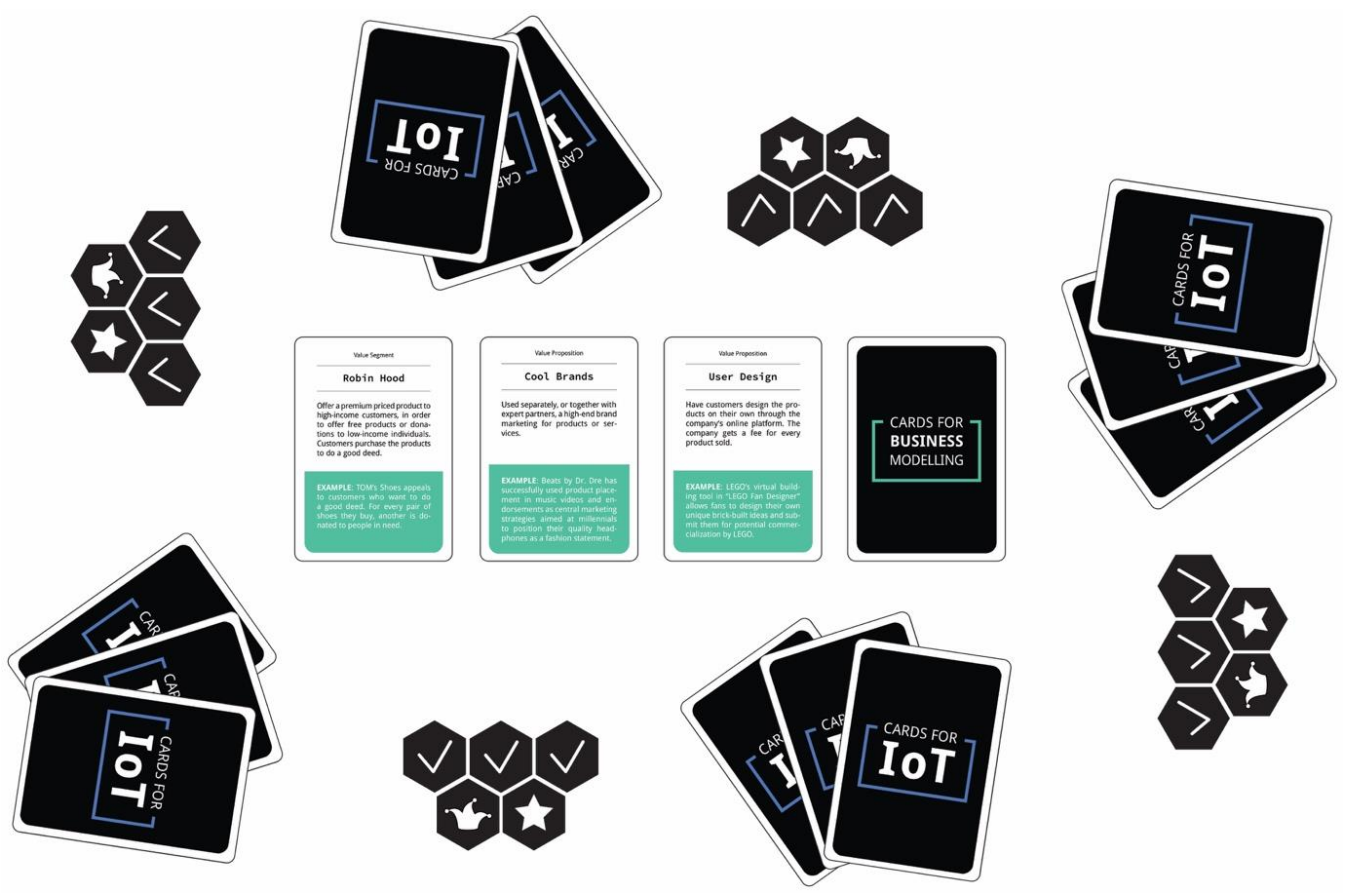

Figure 6: The visual setup of the physical loT Game.

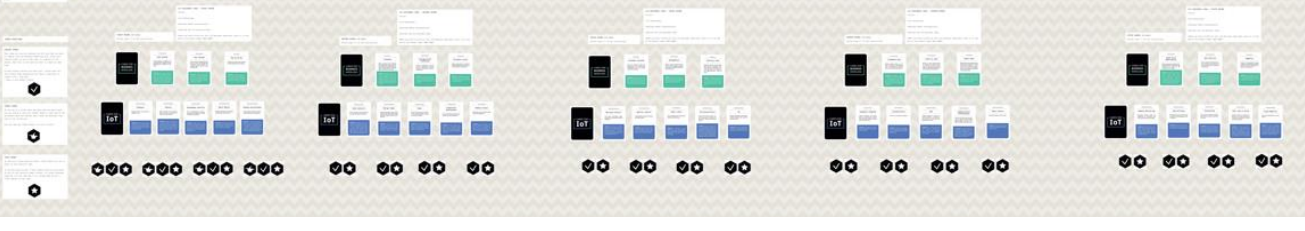

Figure 7: A visual of the digital Padlet version of the loT Game, which each group were assigned to play through.

\subsection{M4: Gamifying a method}

In the fourth module, we discussed and worked with how creativity can be supported through collaboration across platforms. The focus was on applying theory and methods learned throughout the previous modules to gamify an interview method based on an existing game's set of rules. Each step of the design thinking process was explained, the groups set to work, returned with their results, before the next step was explained, and the groups returned to their workshop development.

This part of the course took the students back to an abstract conceptualization by being presented to and trying to understand the given interview method. From there, the design process took the students into active experimentation, transforming assimilative into accommodative knowledge.

\subsection{M5: Presentation and testing of games + theory reflection}

The fifth module of the course focuses on reflection on creativity concerning the passion and curiosity that can be found in individuals. Here the students were introduced to the autotelic personality, intrinsic and extrinsic motivation (Vallerand 2000), as well as the concept of flow (Nakamura \& Csikszentmihalyi 2014). Each group tested their game with a student from one of the other groups and finally presented their prototypes. With this module, the students completed their second round of Kolb's experiential learning cycle. The initial presentation of abstract concepts in the form of theories on creativity is transformed into concrete experiences, which in turn are transformed into a new understanding of creativity using the design thinking process. As part of the 
concluding discussion of the whole course, the students reflected on their design process and the new insights created by their research through design (Gaver 2012).

\section{Through an Experiential Learning Cycle}

The structure of the course is built around the experiential learning cycle, to ensure the students, even though digital present, still were introduced to hands-on experimentation facilitating their learning. This placed the two games as centrepieces of the course providing the students with concrete experiences of being creative through games as a method. Building up to the gameplay, we provide the students with assimilative knowledge through the contextualizing of creativity and gameplay. This sets the frame for the students for accommodating knowledge, putting it into action through game creation and active experimentation as the beginning of an upward spiral through Kolb's experiential learning cycle, as visualized in figure 8.

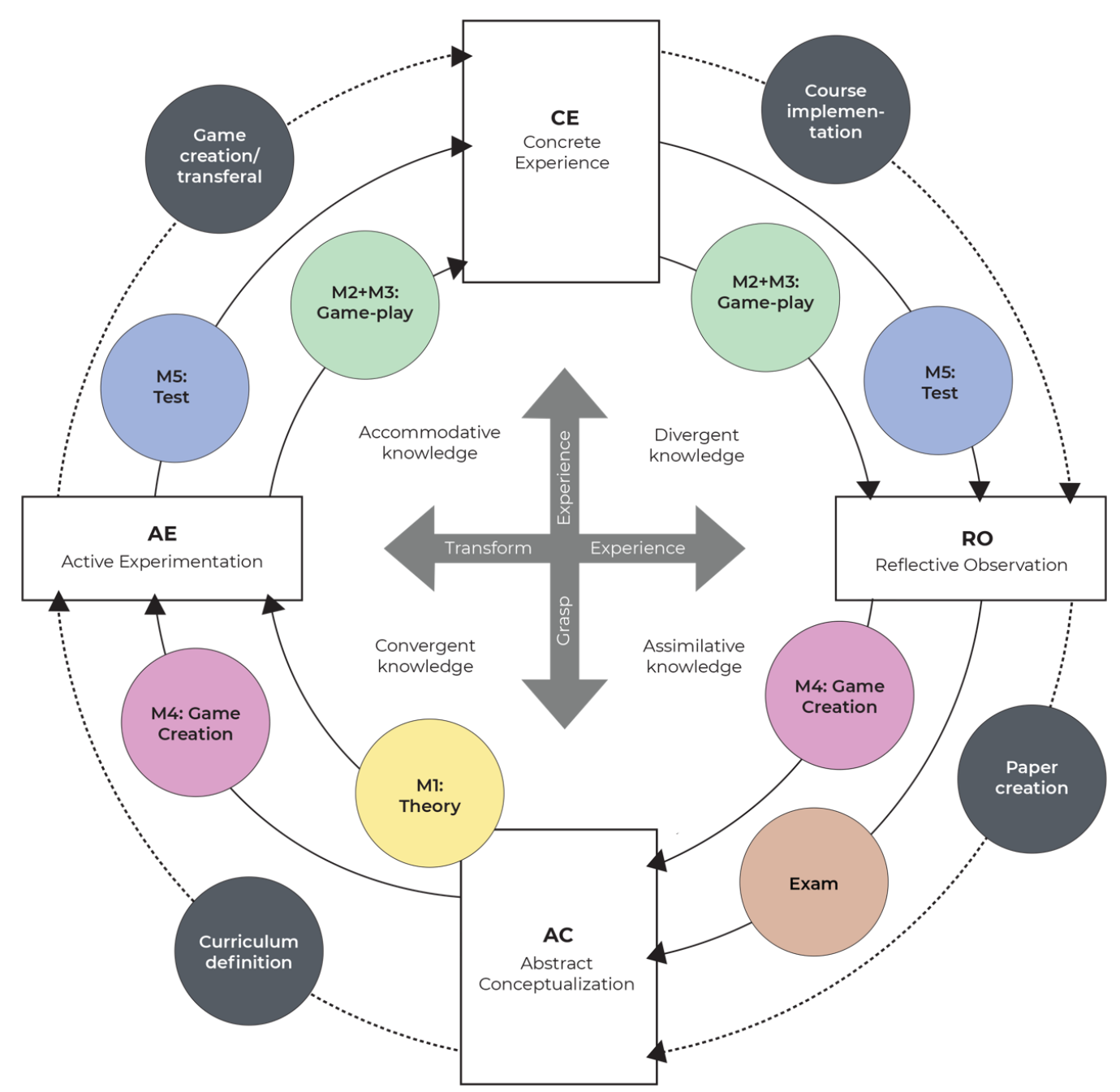

Figure 8: The Creativity \& Competences course's learning spiral built on Kolb's (2015) experiential learning.

Figure 8 shows the course's learning spiral based on Kolb (2015). Starting at AC with M1, the students' learning process evolves based on the modules of the course. As can be seen in the figure, the students expand their understanding of the abstract conceptualizations of the presented theories in $\mathrm{M} 1$ through active experimentations. This happens through the games in $\mathrm{M} 2$ and $\mathrm{M} 3$, which intend to move the students from active experimentation to concrete experience. Meaning, 
they play design games to obtain hands-on knowledge of creativity evolved through gameplay. In the reflection and recap (see figure 3) many of the students underlined that by playing the games, they came up with ideas they would never have thought of if it was not for the gameplay. Moving to M4 and M5, the students were asked to apply their newly experienced approach to creativity and create their games and test them. This pushed them into grasping the experience, and in turn, transform it into a new understanding and accommodation of the presented and experienced knowledge. This process in a design education context initiates a second-order walkthrough of Kolb's learning cycle, based on design thinking (see figure 9).

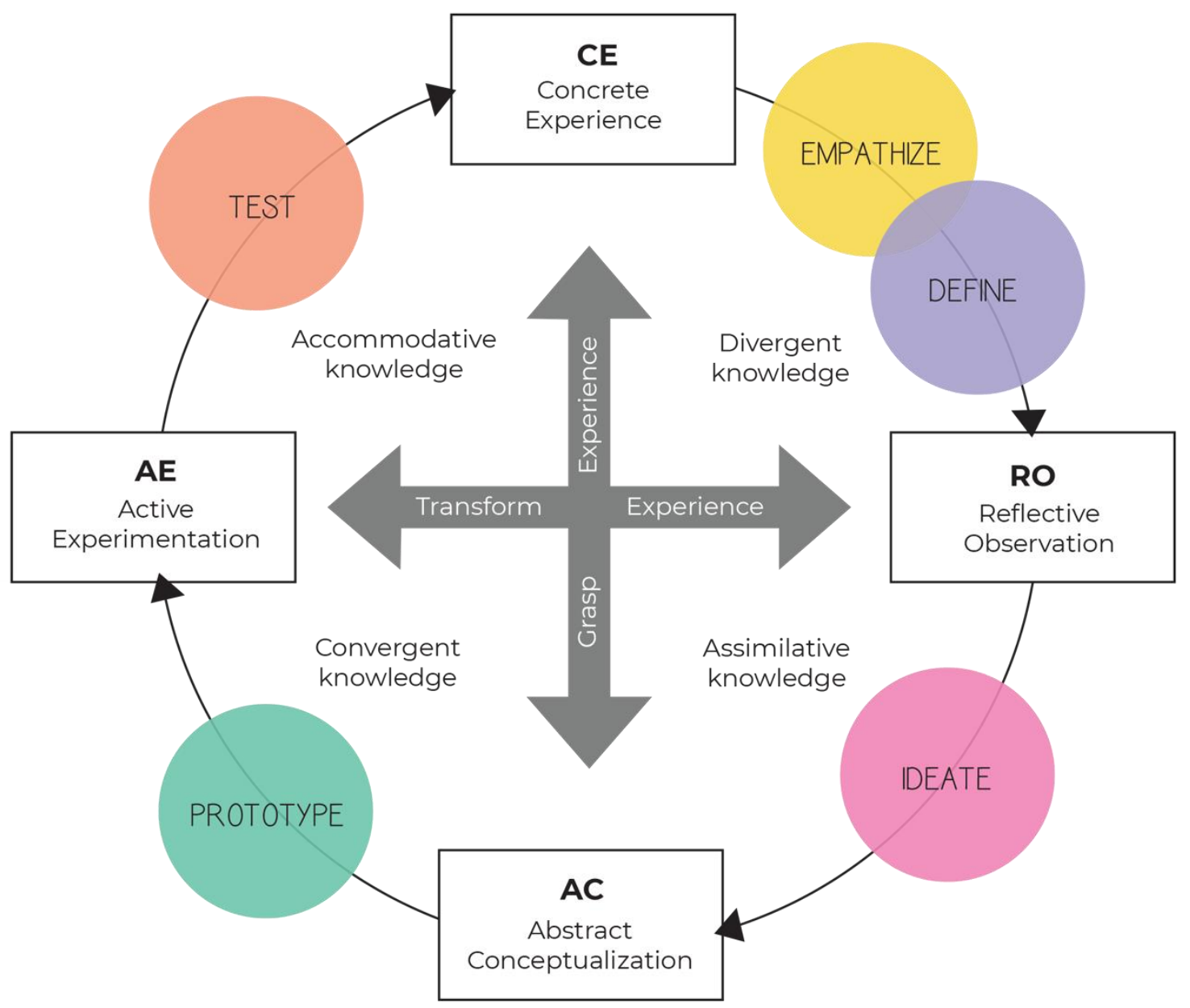

Figure 9: Kolb's learning cycle with the different phases of a design thinking process.

The students' tasks in M4 and M5 were the design of a method and testing it. Thus, embedding a very small design process in the experiential learning cycle. The design process takes its starting point from the concrete experiences of the OMGame and Cards of loT. At the same time, the empathize and define steps of the design thinking process are grounded in the student's knowledge of interview methods, already acquired earlier in their education. Through reflection on their own experiences as well as the described user scenario, brainstorming and ideation can begin. Their ideas must be concordant with the various methods as well as creativity theories, already part of the course curriculum. The prototype converges knowledge once again, enabling active experimentation through the test, gaining a concrete experience with the theoretical knowledge and design process. This is concluded in the course itself through the discussion by the students and their reflection on their observations. The exam ends this walkthrough of the learning cycle with its reflection on reflection on action (Schön 1987). 
This process made the students reflect upon how they could use this type of method in their project work and with potential case partners, as well as designing a game being a design practice in itself. The students here underlined, that it was hard to gamify an interview method (see M4), but when it was contextualised as being a design process with steps to go through, they started applying game elements and testing. Quickly, they started experimenting with the limits and potentials of gamebased methods.

The outer cycle with the dotted line in figure 8 indicates the teachers' learning process in creating and executing the course. This was added to the experiential learning spiral because, in these changing times, experimentation and experiential learning is just as much a learning process for the teachers in design education as the course content is for the students. This shows, how rethinking design education is a process of experimenting with formats across media, time, and space.

\section{Key insights}

Despite the challenges of the transition to a digital format, the creative process was still present, and ideas were being developed, such that the students themselves had not imagined possible. In our discussions with the students, they expressed their ability to think outside the box. By making them comfortable with engaging actively in the games and the development of the prototypes, we provided them with the opportunity to go beyond the ideation step. If we had transferred the course into pure lectures and left the active experimentation and experience to the students themselves, they would not have been able to obtain the same learning experience. This underlines the importance of hands-on experiences in the digital space.

These were made possible by translating our games into digital versions where interaction possibilities and the hands-on element in teaching design were preserved, even broadened. During the lessons, the dialogue took place through online channels while the participants gathered around a digital game board. Despite the distance and lack of tactility in the game situation, the many components of the game could still be interacted with through the digital game board. The students got concrete experiences before moving on to the next stage in their learning cycle.

The structure of the modules was planned to ensure a continuous expansion of knowledge and reflection by adding to the student's knowledge module by module. In module $2+3$ the students were given a quick contextualisation of the methods before we asked them to play the development games. It was impressive how easy it was for the students to start playing and developing new ideas within a context they were unfamiliar with after being offered merely a short introduction. There was a great commitment to the games within the individual groups and rather lively dialogue. At the same time, the students interacted well with their digital game boards. This indicates that the stepby-step build-up of the modules around the experiential learning cycle supports the student's knowledge acquisition.

To our surprise, at the very first module, the students expressed concern regarding the use of Zoom, breakout rooms, and even Teams. They had not been introduced to these platforms before, despite several lockdowns before the course. Thus, our course became their introduction to all the platforms which would be in use during the rest of the term. 


\section{Conclusion}

Through the presented case study, we explored how we can rethink hands-on learning in a digital space by applying an experiential learning approach combined with a design thinking process and game-based methods to facilitate creativity.

While there are challenges that need to be overcome, our case shows the huge potential in creating an engaging digital experiential learning environment. One difficulty for the students is to stay focused in digital workshop settings because the dialogue is limited. If multiple people speak at once, it is impossible to hear any of them. The inability to properly decode facial expressions and body language causes the students to feel somewhat emotionally disconnected from one another. Workgroups of three to five students ensure active discussions, as well as providing a manageable space for engagement and brainstorming.

Getting started with the workshops can be difficult for the students, especially when the coursework consists of games because there is a lot of information and rules to understand. Therefore, the students must be thoroughly introduced to the context, expectations, and rules of the workshop setting, to the extend, that they do not need a teacher as a facilitator to guide, for instance, idea development. This case study shows that the students could facilitate their own learning experience. By providing the students with the contextualisation of the games they were to play, and the basics of gamification, we created a learning environment in which the students facilitated the workshops and prototyping processes themselves, mostly.

Using Kolb's experiential learning cycle as our basis for the course development, gave us as teachers a clear-cut framework to ensure a progression throughout the course. The design thinking process gave second-order learning as the students themselves realized how the theories and their concrete experiences gave way to a new understanding, an accommodation of the course materials. Kolb's cycle becomes a spiral, and the design thinking process creates a new awareness for the student within their learning process. We argue that the lockdown's requirement to go online with the full course gave way to a deeper understanding of the course material than we experienced with former student groups, who only encountered a traditional face-to-face course.

\section{References}

Amabile, T. M. (1998). How to kill creativity (Vol. 87). Boston, MA: Harvard Business School Publishing.

Csikszentmihalyi, M. (2014). Society, Culture, and Person: A Systems View of Creativity in Csikszentmihalyi, M., The Systems Model of Creativity. Springer Science+Business Media, Dordrecht.

Gaver, W. (2012, May). What should we expect from research through design? In Proceedings of the SIGCHI conference on human factors in computing systems (pp. 937-946).

Kolb, D. A. (2015). Experiential learning: Experience as the source of learning and development second edition. Pearson FT press.

Kolmos, A., Krogh, L., \& Fink, F. (2007). The Aalborg PBL model. Aalborg University Press.

Madsen, K. M., \& Krishnasamy, R. (2020). Our Museum Game: A Collaborative Game for UserCentered Exhibition Design. I A. Brooks, \& E. I. Brooks (red.), ArtsIT 2019: Interactivity \& Game Creation (p. 427-435). Springer. https://doi.org/10.1007/978-3-030-53294-9_31

Madsen, K. M., \& Rasmussen, M. H. (2021). A Matrix for Gamifying Development Workshops. In A. Brooks, E. I. Brooks, \& D. Jonathan (red.), Interactivity \& Game Creation: 9th EAl International 
Conference, ArtsIT 2020 (vol 367, p. 180-197). Springer. https://doi.org/10.1007/978-3-030-734268_10

Nakamura J., Csikszentmihalyi M. (2014) The Concept of Flow. In: Flow and the Foundations of Positive Psychology. Springer, Dordrecht.

Rhodes, M. (1961). An Analysis of Creativity in The Phi Delta Kappan, Vol. 42, No. 7, side 305 - 310.

Schön, D. A. (1987). Educating the reflective practitioner: Toward a new design for teaching and learning in the professions. Jossey-Bass.

Stanford d.school. (2019, June 15). Design Thinking models. Empathize IT. https://empathizeit.com/design-thinking-models-stanford-d-school/ (last accessed 2021, March 21).

Vallerand, R. J. (2000). Deci and Ryan's Self-Determination Theory: A View from the Hierarchical Model of Intrinsic and Extrinsic Motivation. Psychological Inquiry, 11(4), 312-318.

Author Bios:

Kristina Maria Madsen, Ph.D., is an Assistant professor at Aalborg University Business School with a research interest in business design thinking and game-based methods. Kristina's research focuses on exploring games as a strategic design tool for co-creation and innovation in business design.

Thessa Jensen, Ph. D., is an Associate Professor at Aalborg University, Denmark. Her research focus are communities on online platforms. Problem-based learning is part of her education and research foundation. Since 1992, Jensen has taught both face-to-face and online courses at the university. 